\title{
Apresentação Difusão do Conhecimento: Tendências e Perspectivas
}

https://doi.org/10.21814/uminho.ed.43.3

\section{Cicilia M. Krohling Peruzzo}

Programa de Pós-Graduação em Comunicação, Faculdade de Comunicação Social, Universidade do Estado do Rio de Janeiro (UERJ) e Universidade Federal do Espirito Santo, Departamento de Comunicação, Vitória-ES, Brasil 

A publicação do presente livro intitulado Revistas científicas de Comunicação ibero-americanas na política de divulgação do conhecimento: tendências, limitações e os desafios de novas estratégias, um projeto um tanto postergado, se concretiza em boa hora diante da atual proeminência do debate necessário sobre as questões envoltas na problemática das métricas de avaliação da produtividade científica no campo da Comunicação. Esse tempo de latência dos textos apresentados nos eventos do Fórum de Publicações e Difusão do Conhecimento Científico (FPDCC), da Confederação Ibero-Americana das Associações Científicas e Acadêmicas de Comunicação (Confibercom), no período de 2011 a 2016 e que compõem esta coletânea, permitiu, em alguns casos, uma oportuna atualização das temáticas pelos autores, de modo a contribuir para a discussão ora candente sobre as políticas de divulgação e de avaliação do conhecimento científico no campo da Comunicação Social ibero-americano.

A presente coletânea reúne uma seleção de textos apresentados em painéis e seminários do referido fórum, nas edições realizadas em São Paulo (2011), Quito (2012), Porto (2013), Braga (2014), São Paulo (2015) e Madrid (2016) ${ }^{1}$, cujos autores enviaram suas contribuições escritas. As atividades do FPDCC aconteceram como parte da programação dos congressos da Confibercom, exceto em 2016, que foi realizado no bojo do "V Congreso da Asociación Española de Investigación de la Comunicación (AE-IC)". Ao longo desse tempo, os membros da Comissão do FPDCC e convidados discutiram várias temáticas importantes envolvidas na questão da difusão do conhecimento científico, entre elas, as políticas de indexação de periódicos, de avaliação de periódicos pelo fator de impacto, acesso aberto e circulação do conhecimento, dificuldades e limites da internacionalização, ou seja, de publicação de artigos da área da Comunicação em periódicos científicos do mundo anglo-saxão. Elaboraram também diagnósticos sobre o panorama das revistas científicas em diferentes países, além de tecerem propostas visando o fortalecimento da divulgação da produção científica em Comunicação e incentivando avanços na integração interpaíses da região e maior penetração na pesquisa ibero-americana em Comunicação internacionalmente.

Todos estes aportes estão tratados nos capítulos desta coletânea. 0 primeiro capítulo apresenta "O programa SciELO e o acesso aberto via dourada", de autoria de Abel L. Packer, diretor do programa Scientific Electronic Library Online (SciELO), que tem o mérito de ser pioneiro na adoção do acesso aberto, em 1998, para a publicação de periódicos científicos e de tornar-se uma importante plataforma de acesso aberto com projeção mundial. Abel L. Packer descreve o processo de constituição e

\footnotetext{
${ }^{1}$ Neste período, o Fórum de Publicações e Difusão do Conhecimento foi coordenado por Cicilia M. Krohling Peruzzo, então professora da Universidade Metodista de São Paulo (Brasil), e a partir de julho de 2016, a coordenação passou a ser exercida por Antonio Castillo Esparcia, professor da Universidade de Málaga (Espanha), membro da Comissão do FPDCC, desde 2012.
} 
evolução do SciELO, inicialmente criado para dar visibilidade à produção científica brasileira na área da Saúde, mas que atualmente engloba uma rede de coleções de periódicos científicos de várias áreas do conhecimento publicados em países da América Latina e Caribe, além de Espanha, Portugal e África do Sul, a partir das funções de indexação, publicação e interoperabilidade de periódicos e os artigos. 0 autor salienta as limitações da língua portuguesa, no cenário internacional, para a demonstração do que se produz no Brasil, que concentra um alto grau de produtividade em publicações científicas colocando-o como liderança emergente na região, além de apontar os desafios existentes para a melhoria da difusão científica e de indicar as atuais linhas de ação e as perspectivas futuras do SciELO e sua rede de periódicos.

O segundo capítulo traz a contribuição de Eduardo Aguado López, fundador e diretor da Red de Revistas Científicas de América Latina y el Caribe, España y Portugal (Redalyc). Ele apresenta a existência desta base regional de indexação de periódicos, no texto intitulado "Redalyc: una estratégia de comunicación científica regional", um sistema de livre acesso que nasceu sob o lema "a ciência que não se vê não existe". Eduardo Aguado López mostra as múltiplas funcionalidades da Redalyc, inclusive, como sistema de busca por campos do conhecimento e de indicadores bibliométricos e cienciométricos nos campos das Ciências Sociais e Humanas e das Ciências Naturais e Exatas, em seu acervo com mais de 1.300 periódicos. A Redalyc tem como um dos marcos de sua visão a superação da atual avaliação da ciência baseada em métricas como o fator de impacto e impulsionando a inclusão da ciência local e a diversidade linguística em favor do bem comum².

O capítulo "Periódicos científicos e difusão do conhecimento comunicacional: do diganóstico ao debate sobre méticas de avaliação de impacto" resgata os conteúdos discutidos no âmbito dos encontros do Fórum de Publicações do Conhecimento Científico da Confibercom e traz um panorama geral dos periódicos de Comunicação nos países ibero-americanos, para discutir caminhos e propostas para a democratização da difusão científica, inclusive, sobre a importância de resgatar a produção ainda não indexada e valorizar as línguas ibero-americanas. Neste capítulo, se apresenta também as propostas discutidas em diversos encontros do FPDCC, as quais, em síntese, visam maior integração ibero-americana, compartilhamento da produção científica em Comunicação, mudanças nas políticas de difusão e avaliação científica, a criação de repositórios e de índices regionais, além de valorização da produção nos idiomas da região, mas com sua difusão em multilínguas - inclusive o Inglês - potencializando sua internacionalização. Se levanta ainda instigantes questões acerca da avaliação da produção científica, mostrando a base de cálculo do fator de impacto e do índice $\mathrm{H}$ e suas limitações e possíveis condicionamentos.

\footnotetext{
${ }^{2}$ Ver https://www.redalyc.org/redalyc/acerca-de/mision.html
} 
Antonio Castillo Esparcia, Ana Almansa Martínez e Elizabeth Castillero Ostio assinam o capítulo sobre a situação de "Las revistas de Comunicación en el panorama internacional: análisis de la presencia en los sistemas de indexación”, uma reflexão realizada por intermédio de levantamento e análise da presença dos periódicos da região nos sistemas de indexação internacionais. Mostram também o papel preponderante do fator de impacto JRC (Journal Citation Reports da Web of Science) e do SJR (SCImago Journal Rank da Scopus) na avaliação de periódicos, criticam a prescrição de padrões, a partir dos países hegemônicos, e a baixa indexação das revistas de Comunicação ibero-americanas, além de indicarem a existência de outros índices métricos. Concluem ser premente fomentar sistemas de avaliação da qualidade científica respeitando os contextos culturais do âmbito hispano-americano.

No capítulo intitulado "Las revistas científicas en Comunicación: principales retos iberoamericanos actuales", Enrique Bustamante acentua a necessidade urgente de uma cooperação ibero-americana na criação e fortalecimento de índices autóctones e da constituição de redes de distribuição e promoção de revistas científicas de Comunicação. Para ele, a transcendência da Comunicação, que ultrapassa a área do Jornalismo, nas Ciências Sociais, justifica superar os perigos atuais da "colonização" do Inglês que empobrece a investigação e seus resultados diante da hegemonia dos índices anglo-saxônicos que marginalizam as contribuições ibero-americanas e latinas ao submetê-las aos critérios condicionados pelas dinâmicas comerciais dos grandes editoriais.

Em seguida, entra o capítulo de Moisés de Lemos Martins que, sob o título "Políticas científicas e línguas de ciência: o caso das revistas de Ciências da Comunicação em Portugal", aprofunda a problemática do idioma da difusão do conhecimento, reafirmando o Português como língua de ciência, como questão geoestratégica, cultural e de política científica no universo da lusofonia, sem abrir mão da universalidade multilinguística da ciência na era da cultura digital. 0 autor também apresenta um quadro histórico descritivo das revistas de Comunicação, em Portugal, e finaliza apontando a tendência progressiva de publicações linguisticamente híbridas que aceitam a submissão e a publicação de textos em outras línguas, que não exclusivamente o Português, como é o caso do Castelhano e do Inglês.

Eduardo Villanueva Mansilla contribui com o texto "Propuestas para más democracia del conocimiento académico en Comunicación”, no qual tece uma análise crítica sobre as várias configurações estruturais da difusão do conhecimento científico, a partir dos padrões anglo-saxônicos, e constata que na América Latina muito se produz, pouco se circula. Fala da barreira linguística entre Espanhol e Português e do Inglês como idioma de circulação global, mas ressalta que produzir nesta língua, implica afastar-se dos leitores da região, não só pelo idioma, mas porque o circuito de circulação é distinto. No entanto, reconhece que a circulação dos resultados da 
pesquisa, neste idioma, significa também uma forma de documentação e validação internacional. Por fim, propõe um equilíbrio entre as finalidades sociais da pesquisa e certa tendência ensaística da investigação na América Latina e a obediência aos modelos cientificistas predominantes no sistema de divulgação dos países centrais. Aponta ainda a necessidade de fortalecimento dos vários modelos de acesso aberto e das bibliotecas digitais como forma de inclusão, democratização e circulação do conhecimento, além de outras propostas interessantes.

Na sequência, Paulo Serra entra com o capítulo "O acesso aberto e a economia política da publicação científica”, no qual defende o acesso aberto à publicação científica como regra, eliminando, portanto, as restrições do acesso por cobranças de taxas. 0 pesquisador justifica tal posição por ser a ciência uma atividade eminentemente desenvolvida com financiamento público cujos resultados devem beneficiar a sociedade e não gerar lucros aos grandes conglomerados editoriais europeus e/ou estadunidenses que manipulam o fator de impacto como chave dessa apropriação. Paulo Serra explica que a economia política da publicação científica tem, no capitalismo cognitivo, a informação científica (conhecimento) como fonte de valor e a atenção a ela como medida desse valor como bem, sob marcas estrategicamente trabalhadas pelo marketing comercial. Demonstrando profundo domínio sobre os mecanismos da indústria editorial, o autor comenta também a proliferação recente de editores e revistas predatórios, em que os autores pagam pela publicação de artigos que muitas vezes nem sequer são revistos e que anunciam fatores de impacto falsos ou manipulados. Como resposta ao conjunto de toda essa situação que tem consequências desfavoráveis à ética e ao caráter público da ciência, Serra propõe o acesso aberto, que pode ser de vários tipos e, não necessariamente, significa acesso universal.

Um estudo sobre as apropriações das tecnologias digitais por periódicos é apresentado por Carlos Arcila e María Claudia Camargo Camargo no texto intitulado “Difusión científica 2.0: adopción y uso de herramientas digitales por revistas académicas de comunicación en lberoamérica”. Numa era em que tanto se fala nas potencialidades e facilidades representadas pela internet, é interessante conhecer o processo de adoção de ferramentas digitais 2.0 por parte de publicações académicas ibero-americanas de Comunicação. Tomando por base uma amostra de 79 revistas cadastradas na Rede Confibercom de Revistas Científicas de Comunicação (Reviscom), o estudo mostrou a tendência de baixo uso de e-ferramentas, de conteúdos multimídia em outros canais (YouTube, Facebook, etc.) e de práticas de colaboração científica (investigação aberta, participativa e colaborativa). Portanto, se encontravam ainda, à data do estudo, numa etapa inicial de apropriação dos recursos digitais. Os autores comentam os desafios de se inovar nesse patamar e propõem a realização de campanhas sobre os usos e vantagens dos recursos digitais na investigação científica a fim de sensibilizar os investigadores e os encarregados da divulgação das revistas acadêmicas desenvolvendo melhor os processos de empoderamento das tecnologias digitais. 
Fechando a coletânea, entra o capítulo "Política científica y socialización del conocimiento: hacia una nueva economía política común del espacio cultural latino", de autoria de Francisco Sierra Caballero, que tece uma visão globalizante das problemáticas já esmiuçadas nos demais textos e aponta uma série de sugestões na tentativa de encontrar saídas às problemáticas e limites dos setores de produção e difusão do conhecimento em Comunicação. 0 autor analisa criticamente o ecossistema de pesquisa estadunidense e anglo-saxão em mãos de grandes conglomerados editoriais que reúnem a maioria dos periódicos de referência nos diferentes campos do conhecimento com consequências na avaliação da produtividade investigadora e no estabelecimento de hierarquias de validação que limitam o grau de influência das publicações de língua espanhola ou portuguesa e até a própria geração do conhecimento local. Além de falar sobre a necessidade de se avançar em matérias de novas políticas públicas concretas de governo, nos sistemas de Ciência e Tecnologia de Investigação em Comunicação regionais, ele compartilha várias propostas nesse sentido, especialmente de política editorial e financiamento, elaboradas no contexto associativo e acadêmico espanhol, mas com visível aplicabilidade a toda Ibero-América. Por fim, Francisco Sierra Caballero aporta sugestões à Confibercom para a retomada e continuidade de ações diretas em termos de articulação através de plataformas e redes de revistas científicas, realização de meta investigação sobre indicadores e critérios de relevância na difusão do conhecimento, estabelecer políticas de intercâmbio e criação de observatório de revistas, entre outras.

Como o leitor observará, esta obra conjuga textos com dados atualizados e outros com informações mais datadas, fornecendo um enquadramento histórico de questões que continuam a ser estratégicas neste campo. Espero que ao registrar e difundir as contribuições compartilhadas ao longo de seis anos no âmbito do Fórum de Publicações e Difusão do Conhecimento Científico - 2011-2016 - ainda válidas por sua atualidade, e atualizadas para esta obra em alguns casos, este livro possa contribuir para a melhor qualificação dos debates e tomada de decisões acerca das políticas científicas e universitárias de divulgação do conhecimento e avaliação da produção no campo da Comunicação ibero-americano.

Expresso meus agradecimentos à colaboração de Rodrigo Gabrioti na incansável intermediação nos contatos com os autores, bem como por sua cuidadosa revisão dos textos. Agradeço também ao Centro de Estudos de Comunicação e Sociedade (CECS), da Universidade do Minho, pela publicação deste livro porque possibilita o compartilhamento de tantas contribuições importantes aos pesquisadores, editores de revistas científicas, universidades e mentores de políticas públicas de Ciências e Tecnologias, bem como à própria Confibercom, tanto como memória quanto material de apoio propositivo para suas vindouras ações e políticas.

Espero ainda que o compartilhamento das ideias reunidas neste livro possa contribuir efetivamente para a divulgação do conhecimento científico para além dos pares, ou seja, para a comunicação da ciência junto à sociedade como um todo, no 
nível de cada país Ibero-Americano e universalmente. Afinal, a América Latina e os demais países de línguas portuguesa, galega, catalã e espanhola têm muito a dizer à pesquisa em Comunicação mundial. 